\title{
Emerging clinical role of ranolazine in the management of angina
}

\author{
This article was published in the following Dove Press journal: \\ Therapeutics and Clinical Risk Management \\ 14 October 2010 \\ Number of times this article has been viewed
}

\author{
David S Vadnais \\ Nanette K Wenger \\ Division of Cardiology, Emory \\ University School of Medicine, Atlanta, \\ Georgia, USA
}

\begin{abstract}
Chronic stable angina is an exceedingly prevalent condition with tremendous clinical, social, and financial implications. Traditional medical therapy for angina consists of beta-blockers, calcium channel blockers, and nitrates. These agents decrease myocardial oxygen demand and ischemia by reducing heart rate, lowering blood pressure, and/or optimizing ventricular loading characteristics. Unique in its mechanism of action, ranolazine is the first new antianginal agent approved for use in the US for chronic angina in over 25 years. By inhibiting the late inward sodium current $\left(\mathrm{I}_{\mathrm{Na}}\right)$, ranolazine prevents pathologic intracellular calcium accumulation that leads to ischemia, myocardial dysfunction, and electrical instability. Ranolazine has been proven in multiple clinical trials to reduce the symptoms of angina safely and effectively and to improve exercise tolerance in patients with symptomatic coronary heart disease. These benefits occur without reduction in heart rate and blood pressure or increased mortality. Although ranolazine prolongs the $\mathrm{QT}_{c}$, experimental data indicate that ranolazine may actually be antiarrhythmic. In a large acute coronary syndrome clinical trial, ranolazine reduced the incidence of supraventricular tachycardia, ventricular tachycardia, new-onset atrial fibrillation, and bradycardic events. Additional benefits of ranolazine under investigation include reductions in glycosylated hemoglobin levels and improved left ventricular function. Ranolazine is a proven antianginal medication in patients with symptomatic coronary heart disease, and should be considered as an initial antianginal agent for those with hypotension or bradycardia.
\end{abstract}

Keywords: chronic angina, myocardial ischemia, ranolazine, pharmacotherapy, antianginal, sodium current

\section{Introduction}

Although angina pectoris has been diagnosed and treated by physicians for over a century, initial therapies were of limited utility. Brandy, ether, chloroform, and ammonia were commonly prescribed to such patients in the nineteenth century before the application of nitrates was first published in 1867. ${ }^{1}$ Today, cardiovascular disease has tremendous medical, social, and financial impacts on American lives. Approximately 2400 Americans die from cardiovascular disease each day, with over nine million adults reporting angina pectoris. ${ }^{2}$ The estimated direct and indirect cost of coronary heart disease alone in the US exceeds 150 billion dollars annually. For those fortunate to survive a coronary event, much of this burden derives from hospitalizations, physician visits, and lost productivity. Improving control of angina pectoris is critical to optimizing the patient's clinical outcome, quality of life, and the social impact of this condition.

Chronic stable angina results from an imbalance between myocardial oxygen supply and demand in the setting of a fixed atherosclerotic coronary plaque. Modern treatment
Correspondence: Nanette K Wenger 49 Jesse Hill Junior Drive, Atlanta, GA 30303, USA

Tel +l 4046164420

Email nwenger@emory.edu 
Table I Antianginal pharmacologic management

\begin{tabular}{|c|c|c|c|c|}
\hline \multirow[t]{2}{*}{$\begin{array}{l}\text { Determinant of } \\
\mathrm{O}_{2} \text { Demand }\end{array}$} & \multirow[t]{2}{*}{$\begin{array}{l}\beta \text { - } \\
\text { Blocker }\end{array}$} & \multirow[t]{2}{*}{ Nitrates } & \multirow{2}{*}{$\begin{array}{l}\mathrm{Ca}^{++} \text {Blocker } \\
\text { Dihydropyridine }\end{array}$} & \multirow{2}{*}{$\begin{array}{l}\mathrm{Ca}^{++} \\
\text {Blocker } \\
\text { Verap/ } \\
\text { Dilt } \\
\end{array}$} \\
\hline & & & & \\
\hline Heart rate & $\downarrow \downarrow$ & 0 & $\uparrow / \uparrow \uparrow$ & $\downarrow \downarrow$ \\
\hline Afterload (BP) & $\downarrow$ & $\downarrow$ & $\downarrow \downarrow \downarrow \downarrow$ & $\downarrow \downarrow$ \\
\hline Preload & 0 & $\downarrow \downarrow \downarrow$ & 0 & 0 \\
\hline Contractility & $\downarrow \downarrow$ & $\uparrow$ & $\uparrow \uparrow$ & $\downarrow \downarrow$ \\
\hline \multicolumn{5}{|l|}{$\begin{array}{l}\text { Determinant of } \\
\mathrm{O}_{2} \text { supply }\end{array}$} \\
\hline Vasomotor tone & $\uparrow$ & $\downarrow \downarrow$ & $\downarrow \downarrow \downarrow \downarrow$ & $\downarrow \downarrow \downarrow \downarrow$ \\
\hline
\end{tabular}

Abbreviations: BP, blood pressure; verap/dilt, verapamil/diltiazem; 0, no effect. Reprinted from Stone P. Ranolazine: new paradigm for management of myocardial ischemia, myocardial dysfunction, and arrhythmias. Cardiol Clin. 2008;26:603-6I4. ${ }^{58}$ Copyright @ 2008, with permission from Elsevier.

for chronic angina consists of medications and revascularization, with the latter serving primarily an adjunctive role. ${ }^{3,4}$ Conventional medical therapy improves the ischemic imbalance leading to angina by reducing the heart rate, blood pressure, and/or preload while optimizing ventricular contractility, leading to a reduction in myocardial oxygen demand (Table 1).

Therapeutic advances in treating patients with stable angina during the past half century were initially robust. Beta-blockers, first introduced in 1962, have largely become the first-line treatment for patients with coronary heart disease because of the post-myocardial infarction mortality reduction seen with this class of agents. ${ }^{5-7}$ Revascularization for coronary heart disease began with coronary artery bypass graft surgery in 1967, followed by percutaneous transluminal coronary angioplasty in 1977 . However, after the introduction of calcium channel blockers in the 1980s, it was not until ranolazine was approved by the Food and Drug Aministration in 2006 that a novel medical therapy became available for the treatment of chronic stable angina. Ranolazine is a proven antianginal agent that, unlike beta-blockers, nitrates, or calcium channel blockers, does not affect either heart rate or blood pressure. ${ }^{8}$ Understanding ranolazine's unique mechanism of action has led to the discovery of several investigational applications beyond the control of chronic angina symptoms.

\section{Mechanism of action}

Under normal physiologic conditions, cardiac myocyte function is characterized by a balance between sodium influx and efflux mechanisms. Cellular depolarization results from rapid activation of membrane sodium channels (peak $\mathrm{I}_{\mathrm{Na}}$ ) leading to inward flux of sodium ions (Phase 0). ${ }^{9}$ The peak $\mathrm{I}_{\mathrm{Na}}$ channels rapidly inactivate, leading to a sustained but short intracellular accumulation of sodium (Phase 2). The intracellular sodium then permits release of calcium intracellularly from the sarcoplasmic reticulum, which binds with actin and myosin, leading to myocardial contraction. Intracellular homeostasis is restored, with transport of the sodium and calcium extracellularly by the sodium/potassium-ATPase $\left(\mathrm{Na}^{+} / \mathrm{K}^{+}\right.$-ATPase $)$and the sodium/calcium $\left(\mathrm{Na}^{+} / \mathrm{Ca}^{2+}\right)$ exchanger, respectively.

In pathologic states, such as ischemia, left ventricular hypertrophy, and heart failure, there is a prolonged late sodium current (late $\mathrm{I}_{\mathrm{Na}}$ ) during Phase 2 of the action potential. ${ }^{9} 10$ Excess intracellular sodium results in intracellular $\mathrm{Ca}^{2+}$ overload via reverse transport across the $\mathrm{Na}^{+} / \mathrm{Ca}^{2+}$ exchanger. Sustained myocardial contraction ensues, eventually leading to myocardial dysfunction, electrical instability, increased diastolic wall tension, and mitochondrial dysfunction. ${ }^{11}$ Ultimately, the increased diastolic wall tension causes compression of the vascular beds, leading to further reduction of coronary blood flow, increased myocardial oxygen demand, and eventual cellular necrosis (Figures 1 and 2).

Original investigations of ranolazine attributed its antiischemic effects primarily to selective inhibition of fatty acid oxidation, thus shifting metabolism to more energyefficient glucose oxidation. ${ }^{12-15}$ Alternative explanations of ranolazine's mechanism of action involving $\beta 1$ - and $\beta 2$-adrenoceptor inhibition have also been proposed. ${ }^{16}$ Subsequent studies, however, have largely disproven these theories and concluded that ranolazine's mechanism of action, at therapeutic serum levels, primarily involves inhibition of the late $\mathrm{I}_{\mathrm{Na}}{ }^{17-19}$ By inhibiting the late $\mathrm{I}_{\mathrm{Na}}$, ranolazine prevents intracellular calcium overload and its subsequent deleterious electrical and mechanical effects. Therefore, under ischemic conditions, ranolazine's effects are two-fold. First, it attenuates the abnormally prolonged and dysfunctional myocardial contraction that increases myocardial oxygen demand. At the same time, ranolazine is thought to improve coronary blood flow and myocardial oxygen supply by optimizing diastolic function. Ranolazine appears to have little effect on normal resting myocytes, where the contribution of late $\mathrm{I}_{\mathrm{Na}}$ is minimal. ${ }^{20}$ Thus, ranolazine targets a unique downstream component of the ischemic cascade, only under pathologic conditions, to provide its antianginal benefit (Figure 3).

While inhibition of the late $I_{\mathrm{Na}}$ by ranolazine causes shortening of the action potential duration, it also inhibits the delayed potassium rectifier $\left(\mathrm{I}_{\mathrm{Kr}}\right)$, which can lengthen 
the action potential duration. ${ }^{21}$ Lengthening of the action potential duration, early afterdepolarizations, delayed afterdepolarizations, triggered activity, and increased transmural dispersion are each a substrate for ventricular and atrial arrhythmias. The net effect of ranolazine, however, depends on the relative concentrations of these channels in the myocardium and conduction system. Late $\mathrm{I}_{\mathrm{Na}}$ channels are abundant within the Purkinje fibers and midmyocardial cells, resulting in a shortening of the action potential duration. Moreover, several preclinical trials have demonstrated that ranolazine actually reduces afterdepolarizations, delayed afterdepolarizations, triggered activity, and transmural dispersion, suggesting a potential antiarrhythmic effect of ranolazine. ${ }^{21-25}$

\section{Clinical applications Stable angina}

Several clinical trials have investigated the use of ranolazine in patients with chronic stable angina. Although ranolazine is available as both an oral and intravenous formulation, only the oral sustained-release (SR) formulation is available for clinical use, and was the primary agent used in the clinical trials. However, the initial study investigating the use of ranolazine in chronic stable angina compared immediate-release ranolazine with atenolol and placebo in a randomized, double-blind, crossover design involving 158 patients. ${ }^{26}$ Compared with placebo, ranolazine significantly improved time to angina onset, time to ST segment depression, and total exercise duration, while only the latter was significantly improved when compared with atenolol. All subsequent clinical trials used the SR formulation of ranolazine.

\section{MARISA trial}

In the Monotherapy Assessment of Ranolazine in Stable Angina (MARISA) trial, 191 patients with angina-limited exercise were randomized to ranolazine SR $500 \mathrm{mg}, 1000 \mathrm{mg}$, $1500 \mathrm{mg}$, or placebo twice daily for one week in a doubleblind, four-period, crossover, multicenter study. ${ }^{12}$ All other antianginal therapy, except for sublingual nitroglycerin, was discontinued prior to enrollment. Patients were excluded if the following conditions were present: non-diagnostic electrocardiogram, New York Heart Association Class III or IV congestive heart failure, unstable angina, myocardial infarction, recent ( $<$ two months) coronary revascularization, corrected QT $\left(\mathrm{QT}_{\mathrm{c}}\right)$ interval $>500 \mathrm{msec}$, or any medication known to prolong the QT interval or affect metabolism of cytochrome P450 (CYP) 3A4. Eligible patients were required to have exercise-limiting angina with $\geq 1 \mathrm{~mm}$ horizontal or downsloping ST depression on exercise treadmill testing during a qualifying enrollment phase.

Exercise testing was performed at the conclusion of each treatment phase, during both peak (four hours after dosing) and trough (12 hours after dosing) plasma ranolazine concentrations, to assess the sustainability of a clinical response and establish a dose-response relationship. The MARISA investigators found that ranolazine $500 \mathrm{mg}, 1000 \mathrm{mg}$, and $1500 \mathrm{mg}$ twice daily incrementally increased exercise duration by 94 $\mathrm{sec}, 103 \mathrm{sec}$, and $116 \mathrm{sec}$, respectively. These improvements were all significant $(P<0.005)$ when compared with placebo. Furthermore, dose-related increases in exercise duration at peak, as well as trough, and peak times to $1 \mathrm{~mm} \mathrm{ST} \mathrm{segment}$ depression, and times to angina onset were also demonstrated $(P<0.005)$ (Figure 4).

Safety analysis from MARISA yielded several interesting conclusions. Although ranolazine did prolong the QT by 6-14 msec in a dose-dependent fashion, no patient was discontinued from the study because of QT prolongation. Overall, adverse events were substantially more common with the $1500 \mathrm{mg}$ twice-daily dose compared with the lower doses of ranolazine, leading to higher rates of early withdrawal from the study at this dose. Finally, unlike traditional agents used to treat chronic angina, there were no clinically significant changes in either heart rate or blood pressure at rest or during exercise. In this first major clinical trial in patients with chronic stable angina, ranolazine SR monotherapy improved exercise performance in a dose-dependent fashion, with an acceptable safety profile and without clinically meaningful hemodynamic alterations.

\section{CARISA trial}

The Combination Assessment of Ranolazine in Stable Angina (CARISA) trial investigated 823 adults with chronic angina on concurrent therapy with beta-blockers or calcium channel blockers. ${ }^{27}$ In a randomized, three-group, parallel, doubleblind, placebo-controlled design, patients were randomly assigned to placebo, or ranolazine $750 \mathrm{mg}$ or $1000 \mathrm{mg}$. Qualifying antianginal therapy at the time of enrollment was atenolol $50 \mathrm{mg}$, a once-daily diltiazem $180 \mathrm{mg}$ formulation, or amlodipine $5 \mathrm{mg}$ once a day, which was continued throughout the study. Patient selection was otherwise similar to that described in the MARISA trial. Treadmill exercise responses were assessed after two, six, and 12 weeks of treatment, at both peak and trough drug intervals.

The primary endpoint, exercise duration, was significantly improved in both ranolazine groups (pooled) versus the placebo group (115.6 sec versus $91.7 \mathrm{sec}$, respectively, 


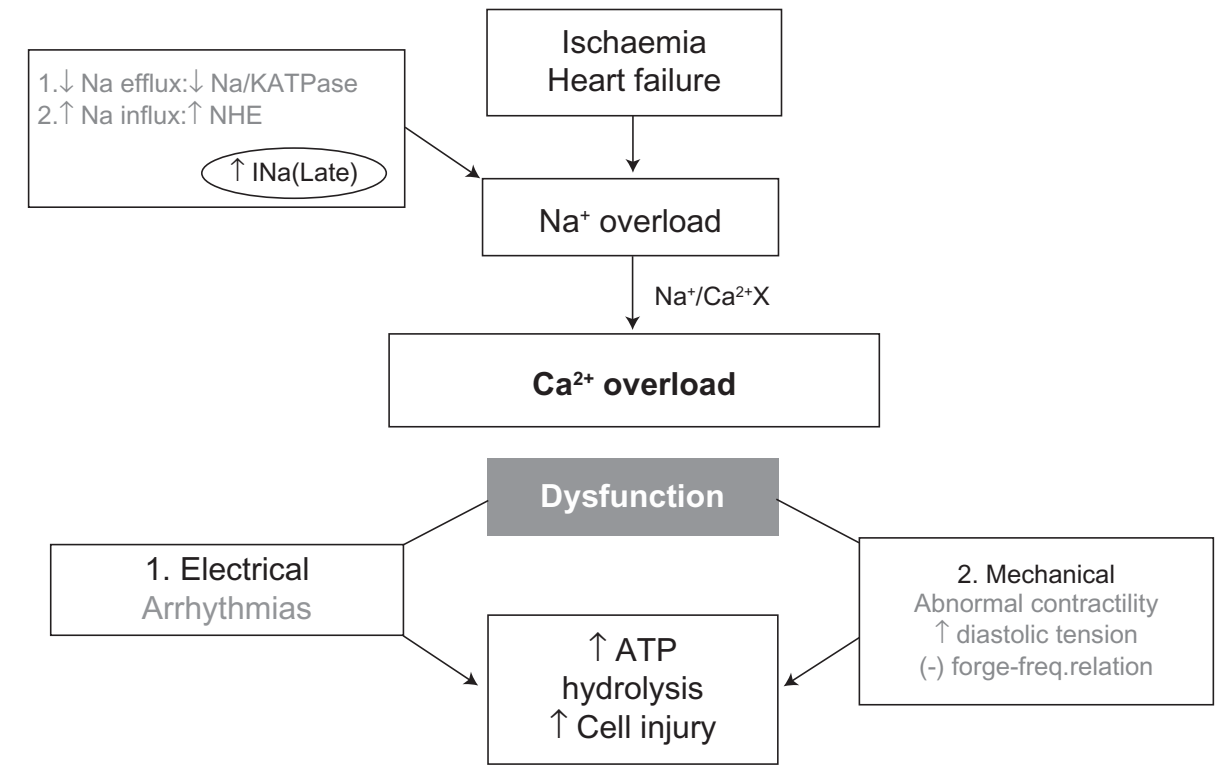

Figure I lonic disturbances in ischaemia and heart failure, and their consequences. Belardinelli L, Antzelevitch C, Fraser H. Inhibition of late (sustained/persistent) sodium current: a potential drug target to reduce intracellular sodium-dependent calcium overload and its detrimental effects on cardiomyocyte function. Eur Heart J. 2004;6 (Suppl I): I3-17."' By permission Oxford University Press, copyright @ 2004.

$P=0.01)$. Exercise duration was increased with ranolazine at both trough and peak, with greater benefit seen at peak concentrations. The response was sustained throughout the 12 weeks of therapy and independent of background antianginal therapy (Figures 5 and 6).

Ranolazine significantly reduced the mean number of angina attacks per week from 3.3 with placebo to 2.5 and
2.1 with ranolazine $750 \mathrm{mg}$ and $1000 \mathrm{mg}$, respectively. Consistent with these findings, nitroglycerin consumption was also significantly reduced with ranolazine compared with placebo, in a similar dose-dependent fashion. Improvements in exercise performance, number of angina attacks, and nitroglycerin consumption were all seen in the absence of alterations in heart rate or blood pressure. The $\mathrm{QT}_{\mathrm{c}}$
A
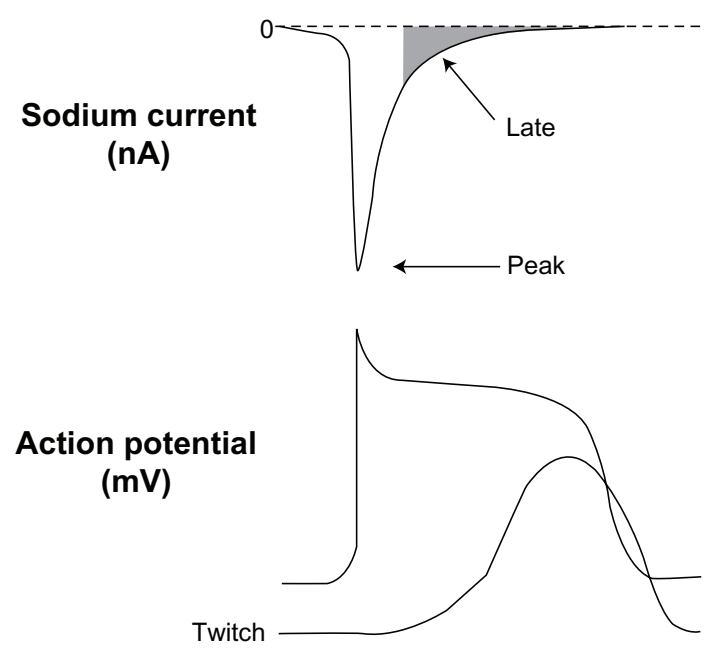

B
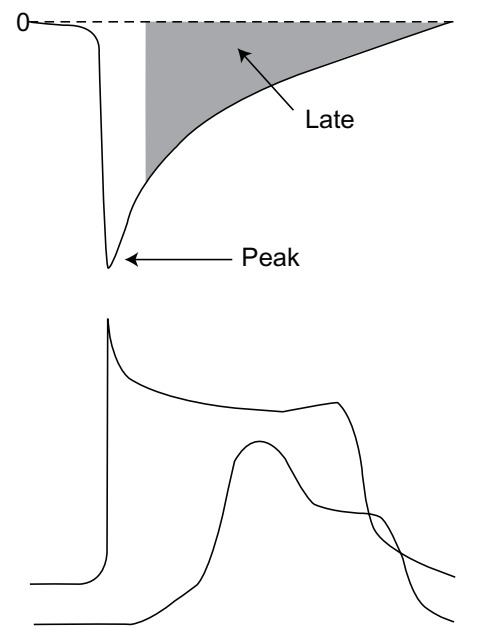

Figure 2 Relation between peak and late sodium current and ventricular action potential (AP) and contraction (tracings are not actual recordings). Panels A and B illustrate a normal and an increased late INa (due to impaired inactivation of $\mathrm{Na}+$ channel), respectively. The enhanced late INa is accompanied by delayed ventricular repolarization (longs APs, and occasional early after depolarization) and abnormal twitch (contraction composed of a phasic and tonic component.) Belardinelli L, Antzelevitch C, Fraser $\mathrm{H}$. Inhibition of late (sustained/persistent) sodium current: a potential drug target to reduce intracellular sodium-dependent calcium overload and its detrimental effects on cardiomyocyte function. Eur Heart J. 2004;6(Suppl I): 13-17."' By permission Oxford University Press, copyright @ 2004. 


\section{Development of Ischemia}

\section{$\uparrow \mathrm{O}_{2}$ Demand}

- Heart rate

- Blood pressure

- Preload

- Contractility

$\downarrow \mathrm{O}_{2}$ Supply

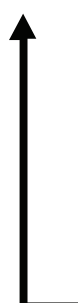

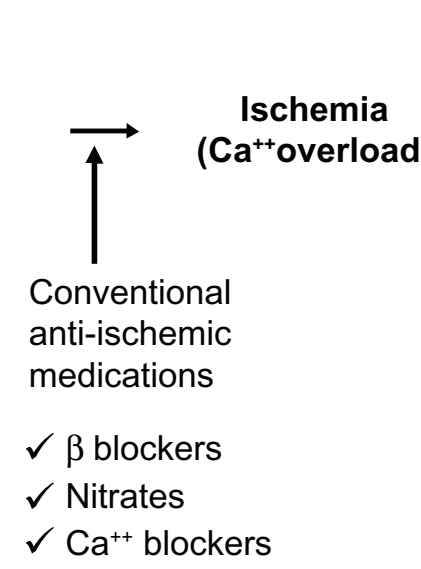

\section{Consequences of Ischemia}

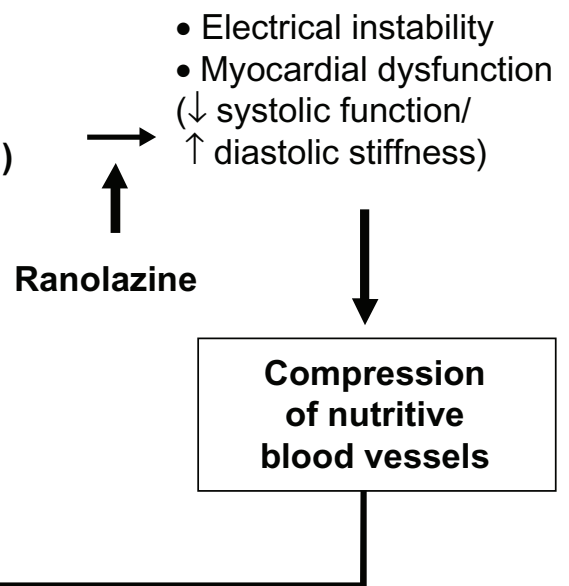

Figure 3 Sites of action of anti-ischemia medication. Reprinted from Stone P. Ranolazine: new paradigm for management of myocardial ischemia, myocardial dysfunction, and arrhythmias. Cardiol Clin. 2008;26:603-614. ${ }^{58}$ Copyright (C) 2008, with permission from Elsevier.

was prolonged $6.1 \mathrm{msec}$ and $9.2 \mathrm{msec}$ by the $750 \mathrm{mg}$ and $1000 \mathrm{mg}$ doses, respectively. No episodes of torsades de pointes were observed.

While the MARISA trial demonstrated ranolazine's efficacy as monotherapy for patients with chronic angina, the CARISA trial was able to demonstrate similar antianginal benefit in those who remained symptomatic despite standard doses of traditional antianginal therapies.

\section{ERICA trial}

The objective of the Efficacy of Ranolazine in Chronic Angina (ERICA) trial was to determine if ranolazine provided additional benefit superimposed on maximal dosing of a conventional antianginal agent. In ERICA, 565 patients with symptomatic ( $\geq$ three angina attacks per week) chronic angina despite amlodipine $10 \mathrm{mg}$ daily were randomized to placebo versus ranolazine $1000 \mathrm{mg}$ twice daily. ${ }^{28}$ Treatment was double-blinded and continued for six weeks. Patient selection was otherwise similar to the previous clinical trials. However, unlike the antecedent trials, the primary endpoint was the frequency of anginal episodes per week, and exercise testing was not performed.

Baseline characteristics were similar between groups, with an average angina frequency of $5.63 \pm 0.18$ episodes per week and nitroglycerin consumption of $4.72 \pm 0.21$ tablets per week. Compared with placebo, ranolazine significantly reduced the frequency of angina attacks $(2.88 \pm 0.19$ on ranolazine versus $3.31 \pm 0.22$ on placebo; $P=0.028)$ and nitroglycerin consumption $(2.03 \pm 0.20$ on ranolazine versus
$2.68 \pm 0.22$ on placebo; $P=0.014)$. Although these results were evident across all subgroups, those with $>4.5$ anginal episodes per week derived a greater treatment effect (Figure 7).

Consistent with the previous clinical trials, ranolazine was well tolerated without significant adverse events. Vital signs remained constant over the treatment period, again highlighting a unique nonhemodynamic effect profile among the currently available antianginal agents. By demonstrating that ranolazine could relieve symptoms in patients with chronic angina on maximal doses of amlodipine, ranolazine was approved in 2006 by the Food and Drug Administration for use in chronic stable angina. ${ }^{29}$

In a recent pilot study, ranolazine up to $1000 \mathrm{mg}$ twice daily was administered to 20 patients with coronary heart disease and who had reversible perfusion defects on exercise treadmill gated single-photon emission computed tomography myocardial perfusion imaging while on conventional antianginal therapy. ${ }^{30}$ Repeat treadmill myocardial perfusion imaging was performed four weeks later, in which quantitative analysis showed significant reductions in the summed stress scores $(P=0.04)$, summed difference scores $(P=0.0037)$, and reversible abnormality on the polar maps $(P<0.05)$. Taken together, these myocardial perfusion imaging findings support an objective improvement in myocardial blood flow with ranolazine. Although this study was limited by lack of randomization, blinding, or a large study population, ranolazine was shown to improve myocardial perfusion and decrease the ischemic burden. 

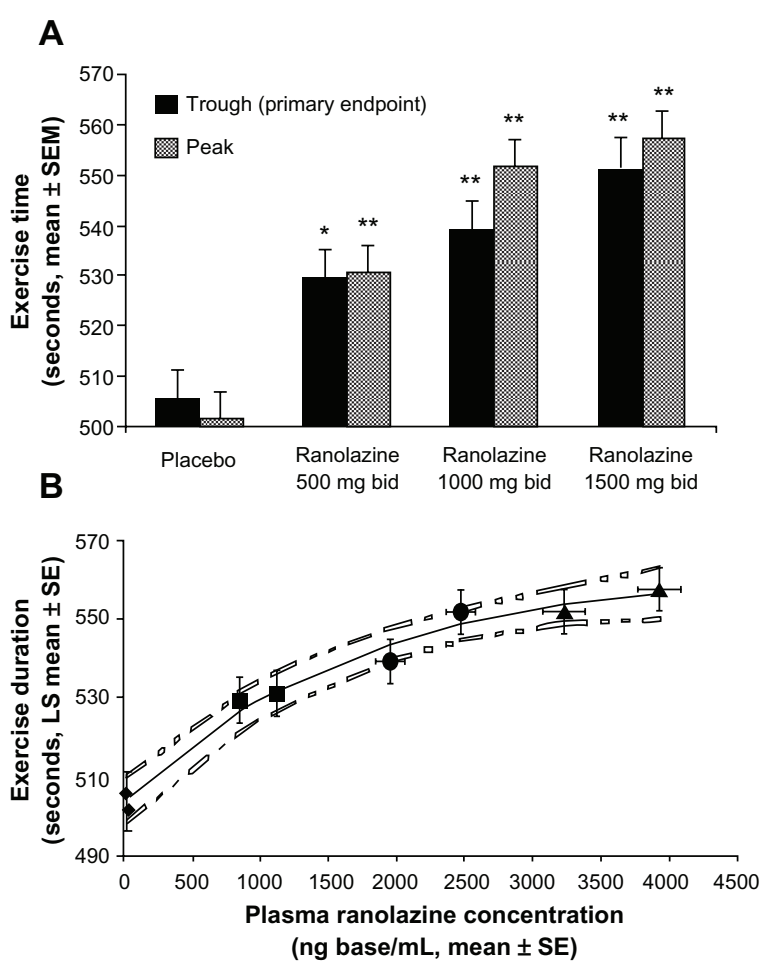

Figure 4 Symptom-limited exercise duration: dose and plasma concentration relationships. A) Exercise duration versus ranolazine dose. Data are shown at trough (solid bars, primary end point) and peak (lined bars). Statistically significant increases were observed on each ranolazine dose versus placebo $(* P<0.005$ vs placebo; ${ }^{* * P}<0.00 \mathrm{I}$ vs. placebo). A dose-response relationship was evident with greater increases at peak than at trough. B) Exercise duration versus ranolazine plasma concentration. Mean exercise duration increases with mean plasma ranolazine concentrations. From left to right, values on each treatment at trough and peak, respectively, are represented by diamonds (placebo), squares ( $500 \mathrm{mg}$ twice daily), circles (I,000 mg twice daily), and triangles (I,500 mg twice daily). Dotted lines represent the $95 \%$ confidence intervals around the fitted curve. Reprinted from Chaitman BR, Skettino SL, Parker JO, et al. MARISA Investigators. Anti-ischemic effects and long-term survival during ranolazine monotherapy in patients with chronic severe angina.J Am Coll Cardiol. 2004;43:1375-1382. ${ }^{22}$ Copyright (C) 2004, with permission from Elsevier.

\section{Acute coronary syndrome MERLIN study}

Although ranolazine had been proven to be safe and efficacious in treating angina for those with chronic stable disease, higher-risk populations had yet to be examined. In the Metabolic Efficiency With Ranolazine for Less Ischemia in Non-ST-Elevation Acute Coronary Syndromes (MERLIN)-TIMI 36 trial, 6560 patients were randomized in a double-blind, placebo-controlled, multinational design to ranolazine or placebo within 48 hours of their non-ST elevation acute coronary syndrome presentation. ${ }^{31}$ Ranolazine was initially administered intravenously, followed by oral dosing at $1000 \mathrm{mg}$ twice daily. Continuous Holter monitoring was performed for seven days after the index event, and median follow-up was 348 days.

Analysis of the primary endpoint (a composite of cardiovascular death, myocardial infarction, or recurrent

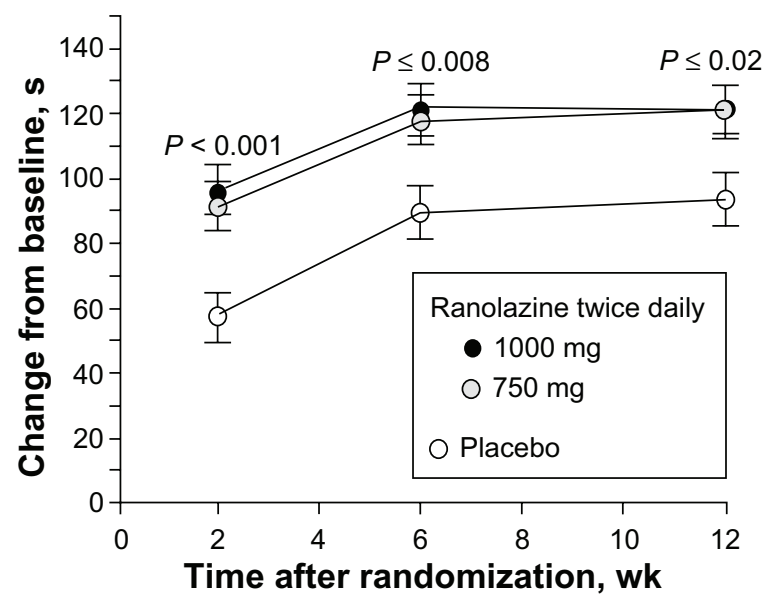

Figure 5 Change in treadmill exercise duration from baseline at trough ranolazine levels over time. Reprinted with permission from Chaitman BR, Pepine CJ, Parker J, et al. Effects of ranolazine with atenolol, amlodipine, or diltiazem on exercise tolerance and angina frequency in patients with chronic severe angina: a randomized controlled trial. JAMA. 2004;291:309-316. ${ }^{27}$ Copyright (C) 2004 American Medical Association. All rights reserved.

Data are least square means (SE). $P$ values are for comparisons of each ranolazine group vs placebo.

ischemia) showed no significant difference between the ranolazine and placebo groups (696 patients [21.8\%] versus 753 patients [23.5\%] respectively; $P=0.11$ ). When the individual elements were evaluated, neither cardiovascular death nor myocardial infarction was found to be significantly

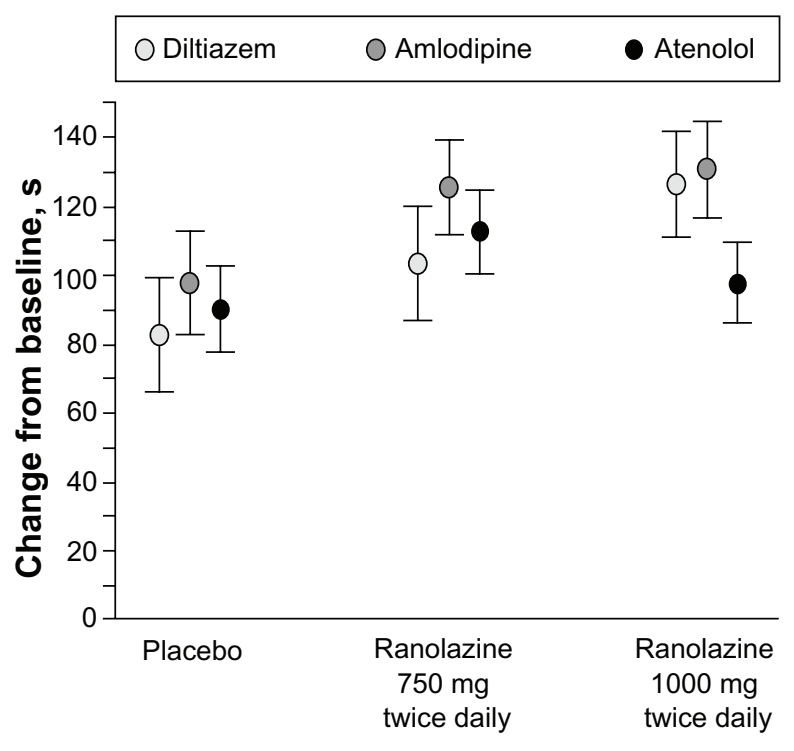

Figure 6 Change in treadmill exercise duration by background antianginal treatment. Reprinted with permission from Chaitman BR, Pepine CJ, Parker J, et al. Effects of ranolazine with atenolol, amlodipine, or diltiazem on exercise tolerance and angina frequency in patients with chronic severe angina: a randomized controlled trial. JAMA. 2004;291:309-316. ${ }^{27}$ Copyright (C 2004 American Medical Association. All rights reserved.

Data are least square means (SE). Treatment $\times$ background interaction $P=0.63$, indicating no statistical evidence of differential treatment effects among background strata. 


\section{A

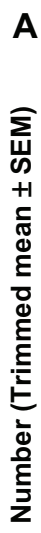

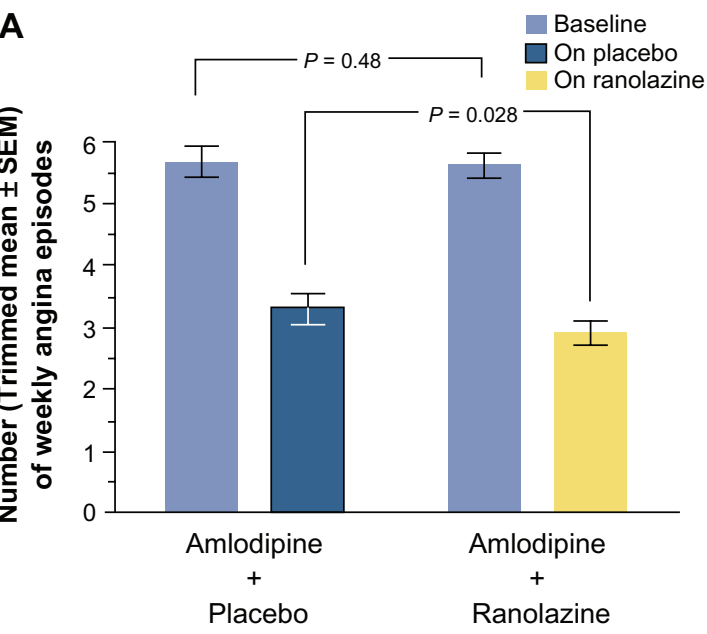$$
\text { B }
$$

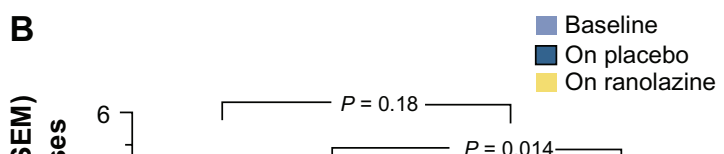
$\square$ On placebo

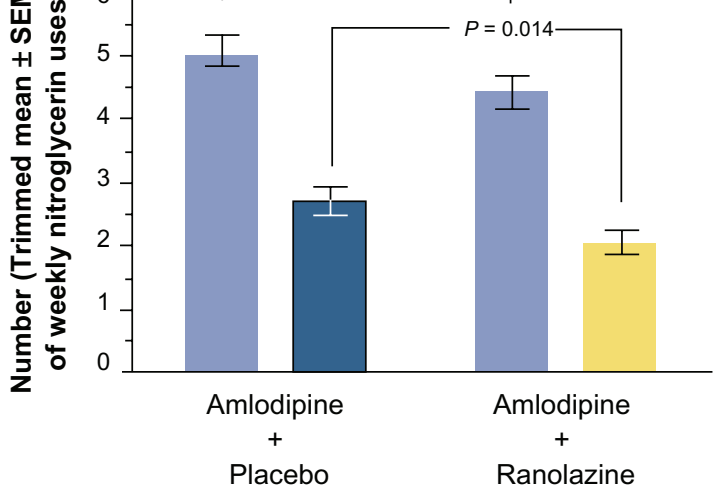

Figure 7 Number of weekly angina attacks (A) and number of weekly nitroglycerin uses (B), excluding patients with weekly angina rate in the top $2 \%$ and bottom $2 \%$ of each treatment group (trimmed mean). SE = standard error of the trimmed mean. Reprinted from Stone P, Gratsiansky NA, Blokhin A, Huang IZ, Meng L. Antianginal efficacy of ranolazine when added to treatment with amlodipine: the ERICA (efficacy of ranolazine in chronic angina) trial. J Am Coll Cardiol. 2006;48:566-575. ${ }^{28}$ Copyright (C 2006, with permission from Elsevier.

different. The incidence of recurrent ischemia, however, was significantly lower in the ranolazine group compared with the placebo group (430 patients [13.9\%] versus 494 patients [16.1\%], respectively; $P=0.03)$. This benefit is likely to be a long-term effect, because post-analysis of the seven-day Holter monitoring post-index event showed no significant difference in the rate of ischemia detected by electrocardiogram (Figure 8). ${ }^{32}$

Although no significant difference was found in the primary endpoint across most major subgroups in the MERLIN trial, including patients treated with intent for a noninvasive strategy, one interesting post hoc analysis result was found with respect to women. Subgroup analysis of the clinical trials using ranolazine prior to MERLIN had found that women showed less improvement than men on exercise testing, with

similar improvements in angina frequency and nitroglycerin consumption..$^{33}$ In the MERLIN trial, however, the effect of ranolazine on the primary endpoint was significant among women ( $\mathrm{n}=2291$; hazard ratio $0.83 ; 95 \%$ confidence interval $0.70-0.99)$, largely driven by a $29 \%$ relative reduction in recurrent ischemia with ranolazine $(P=0.002)$. Further studies are needed to help reconcile these discrepancies.

Unlike previous trials, which used ranolazine only in stable coronary heart disease patients, the MERLIN trial studied a higher-risk population of patients with non-ST elevation acute coronary syndrome. Safety analysis showed no significant difference in death from any cause with ranolazine compared with placebo ( 172 versus $175 ; P=0.91$ ). The incidence of symptomatic documented arrhythmias throughout the duration of the study was also similar in patients treated with ranolazine compared with placebo $(P=0.84)$. Interestingly, the frequency of clinically significant arrhythmias detected by Holter monitoring within the first seven days was significantly lower in the ranolazine group compared with the placebo group (2330 patients [73.7\%] versus 2650 patients [83.1\%]; $P<0.001$ ), a result to be discussed in more detail further on in the article.

A recently published subgroup analysis of 3565 patients with prior chronic angina enrolled in the MERLIN trial demonstrated that, in addition to reducing recurrent ischemia, ranolazine was effective in reducing worsening angina and intensification of antianginal therapy while improving exercise duration. ${ }^{34}$ Conclusions from the MERLIN trial further support previous clinical trial data that ranolazine is effective in controlling angina in symptomatic patients with chronic coronary heart disease. Moreover, ranolazine has a favorable safety profile, even in higher-risk acute coronary syndrome groups, but does not afford any significant reduction in major cardiovascular events, including all-cause death. Beyond its proven antianginal effect, ranolazine may be an effective antiarrhythmic agent, warranting further investigation (Table 2).

\section{Safety}

Individually, clinical trial data demonstrate that ranolazine is generally well tolerated without significant adverse events. The most common adverse events reported include dizziness, constipation, nausea, asthenia, syncope, headache, and abdominal pain. In the MARISA trial, adverse events were markedly lower, ie, $\leq 20.6 \%$ versus $33.2 \%$ with ranolazine dosages at $1000 \mathrm{mg}$ twice daily or less, compared with $1500 \mathrm{mg}$ twice daily. ${ }^{12}$ Subsequently, ranolazine $1000 \mathrm{mg}$ twice daily became the maximum recommended dose. Although five cases of syncope were reported in the CARISA 

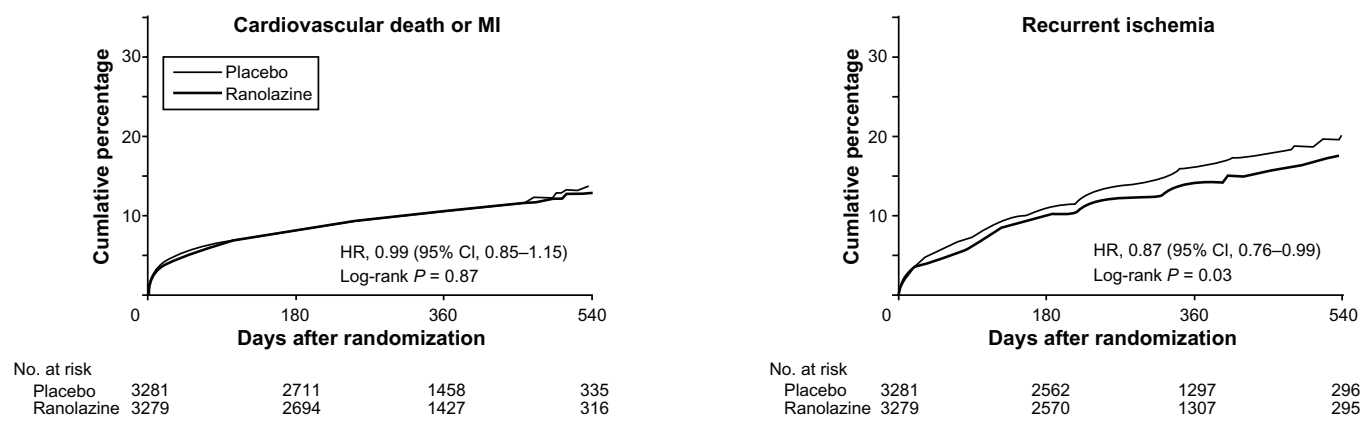

Figure 8 Kaplan-Meier Estimated Rates of Cardiovascular Death or MI and Recurrent Ischemia. Reprinted with permission from Morrow DA, Scirica BM, KarwatowskaProkopczuk E, et al. Effects of ranolazine on recurrent cardiovascular events in patients with non-ST-elevation acute coronary syndromes. JAMA. 2007;297:I775-I783.11 Copyright (C) 2007 American Medical Association. All rights reserved.

Abbreviations: $\mathrm{MI}$, myocardial infarction; $\mathrm{HR}$, hazard ratio; $\mathrm{Cl}$, confidence interval.

trial, which used a maximum $1000 \mathrm{mg}$ twice-daily dose, all cases involved patients on concurrent medications known to raise ranolazine plasma concentrations ${ }^{27}$ Furthermore, there were no reported cases of syncope in the ERICA trial. ${ }^{28}$

The Ranolazine Open Label Experience (ROLE) trial enrolled 746 patients who completed either the MARISA or CARISA trials, with severe functional impairment from angina (mean Duke Treadmill score -14.4), in an open-label extension program.$^{35} \mathrm{After}$ a mean follow-up of 2.82 years, 72 patients $(9.7 \%)$ discontinued ranolazine due to adverse events. Of the reported adverse events, dizziness (11.8\%) and constipation (10.9\%) were the most common. Although the mean $\mathrm{QT}_{\mathrm{c}}$ was prolonged by $2.4 \mathrm{msec}$, there were no treatment discontinuations because of $\mathrm{QT}_{\mathrm{c}}$ prolongation and no reported cases of torsades de pointes. When combining data from the original two trials with that from the ROLE program, the annual mortality for patients with stable coronary heart disease exposed to ranolazine was $2.8 \%$ compared with $>5 \%$ as predicted by the Duke Treadmill score. Consistent with these findings, the MERLIN trial demonstrated that, even in higher-risk patients with non-ST segment acute coronary syndrome, there was no increased cardiovascular death or total mortality with ranolazine. ${ }^{31}$

In evaluating the safety of ranolazine, several specified populations were investigated with encouraging findings. Patients with congestive heart failure enrolled in the ROLE program had lower rates of withdrawal. ${ }^{35}$ As may be expected, the elderly population had higher rates of adverse events, leading to higher rates of ranolazine discontinuation. ${ }^{35,36}$ Serious adverse events attributed to ranolazine, however, did not differ by age group. Similarly, the presence of diabetes, a common comorbidity in patients with coronary heart

Table 2 Efficacy outcomes

\begin{tabular}{|c|c|c|c|c|}
\hline & $\begin{array}{l}\text { Ranolazine } \\
(n=1,789)\end{array}$ & $\begin{array}{l}\text { Placebo } \\
(n=1,776)\end{array}$ & $\begin{array}{l}\text { Hazard ratio } \\
(95 \% \mathrm{Cl})\end{array}$ & $P$ value \\
\hline \multicolumn{5}{|l|}{ Randomization to end of study } \\
\hline Primary end point* & $443(25.2)$ & $503(29.4)$ & $0.86(0.75-0.97)$ & 0.017 \\
\hline Major secondary end point ${ }^{\dagger}$ & $379(21.2)$ & $4 \mid 4(23.5)$ & $0.89(0.78-1.03)$ & 0.12 \\
\hline $\mathrm{CV}$ death or $\mathrm{Ml}$ & $214(11.9)$ & $221(12.5)$ & $0.97(0.80-1.16)$ & 0.71 \\
\hline Recurrent ischemia & $277(16.5)$ & $344(21.1)$ & $0.78(0.67-0.9 \mathrm{I})$ & 0.002 \\
\hline Worsening angina & $96(5.6)$ & $124(8.1)$ & $0.77(0.59-1.00)$ & 0.048 \\
\hline Severe recurrent ischemia & $204(11.9)$ & $245(14.4)$ & $0.81(0.67-0.98)$ & 0.026 \\
\hline Intensification of antianginal therapy & $205(12.5)$ & $260(16.4)$ & $0.77(0.64-0.92)$ & 0.005 \\
\hline \multicolumn{5}{|c|}{30 days until end of study (Landmark analysis) } \\
\hline Primary end point & $338(19.8)$ & $386(23.3)$ & $0.86(0.74-0.99)$ & 0.039 \\
\hline Recurrent ischemia & $226(13.7)$ & $274(17.2)$ & $0.80(0.67-0.96)$ & 0.015 \\
\hline Worsening angina & $92(5.4)$ & $120(7.9)$ & $0.76(0.58-0.99)$ & 0.044 \\
\hline
\end{tabular}

Notes: Data are reported as $n$ (\%), Event rates in parentheses are Kaplan-Meier estimates (\%) at I year. ${ }^{*}$ Cardiovascular (CV) death, myocardial infarction (MI), or recurrent ischemia. ${ }^{\dagger} \mathrm{CV}$ death. Ml, or severe recurrent ischemia.

Reprinted from Wilson SR, Scirica BM, Braunwald E, et al. Efficacy of ranolazine in patients with chronic angina: observations from the randomized, double-blind, placebo-controlled MERLIN-TIMI (metabolic efficiency with ranolazine for less ischemia in non-ST-segment elevation acute coronary syndromes) 36 trial. J Am Coll Cardiol. 2009;53:I5I0-15I6.34 Copyright (C) 2009, with permission from Elsevier.

Abbreviation: $\mathrm{Cl}$, confidence interval. 
disease, was not found to be a predictor of increased adverse events for patients on ranolazine. ${ }^{37}$ Ranolazine appears to be well tolerated, with an acceptable adverse event profile and without increased mortality in the general population with coronary heart disease, including the elderly and those with diabetes or congestive heart failure.

\section{Pharmacokinetics and metabolism}

Ranolazine is available in both oral and intravenous formulations, with only the SR $500 \mathrm{mg}$ tablets approved for clinical use. The oral bioavailability ranges from $35 \%$ to $50 \%$, with food having no effect on the rate or extent of absorption. ${ }^{38}$ The time to maximal plasma concentration with the SR formulation is $4-6$ hours, with a peak-trough ratio at steady state ranging from 1.8-2.2. Effective plasma concentrations, based on clinical trials, range from $2-6 \mu \mathrm{mol} / \mathrm{L} .^{20}$

Ranolazine is extensively metabolized by CYP3A4 enzymes and, to a lesser extent, by CYP2D6. Approximately $5 \%$ is excreted renally unchanged, with advancing degrees of renal failure increasing plasma ranolazine concentrations by 1.7 to $2.0 .{ }^{39}$ Although mild hepatic impairment has no detectable effect on ranolazine metabolism, moderate hepatic impairment significantly increases ranolazine plasma concentrations. ${ }^{40}$

Due to its principal CYP3A4-mediated metabolism, multiple drug-drug interactions are seen with ranolazine. Moderate to potent inhibitors of the CYP3A4 enzyme (ketoconazole, diltiazem, verapamil, macrolide antibiotics, protease inhibitors, and grapefruit juice) can increase plasma ranolazine concentrations by 2.0 - to 4.5 -fold. ${ }^{41}$ Therefore, caution is advised for inhibitors of CYP3A4 when administered with ranolazine. Simvastatin and digoxin do not significantly alter ranolazine levels. The plasma concentrations of these drugs, however, are increased by 2.0- and 1.5-fold, respectively, when given with ranolazine. Inhibitors of P-glycoprotein, verapamil, and cyclosporine can increase the absorption of ranolazine, and similar considerations should be applied.

\section{Investigational clinical applications Arrhythmias}

Despite the modest $\mathrm{QT}_{\mathrm{c}}$ prolongation seen with ranolazine in clinical trials, both experimental and clinical data support a potential antiarrhythmic role for this proven antianginal agent. Ranolazine has multiple cardiac ion channel effects. However, at therapeutic plasma levels, ranolazine primarily inhibits late $\mathrm{I}_{\mathrm{Na}}$ and $\mathrm{I}_{\mathrm{Kr}}{ }^{21}$ Inhibition of these two channels have opposing effects on the action potential duration, with the net effect of ranolazine dependent on the relative concentrations of these channels within the midmyocardial cells and Purkinje fibers (Figure 9).

Prolongation of the action potential duration, in association with early afterdepolarizations, delayed afterdepolarizations, increased transmural dispersion of repolarization, and triggered activity are substrates for both atrial and ventricular

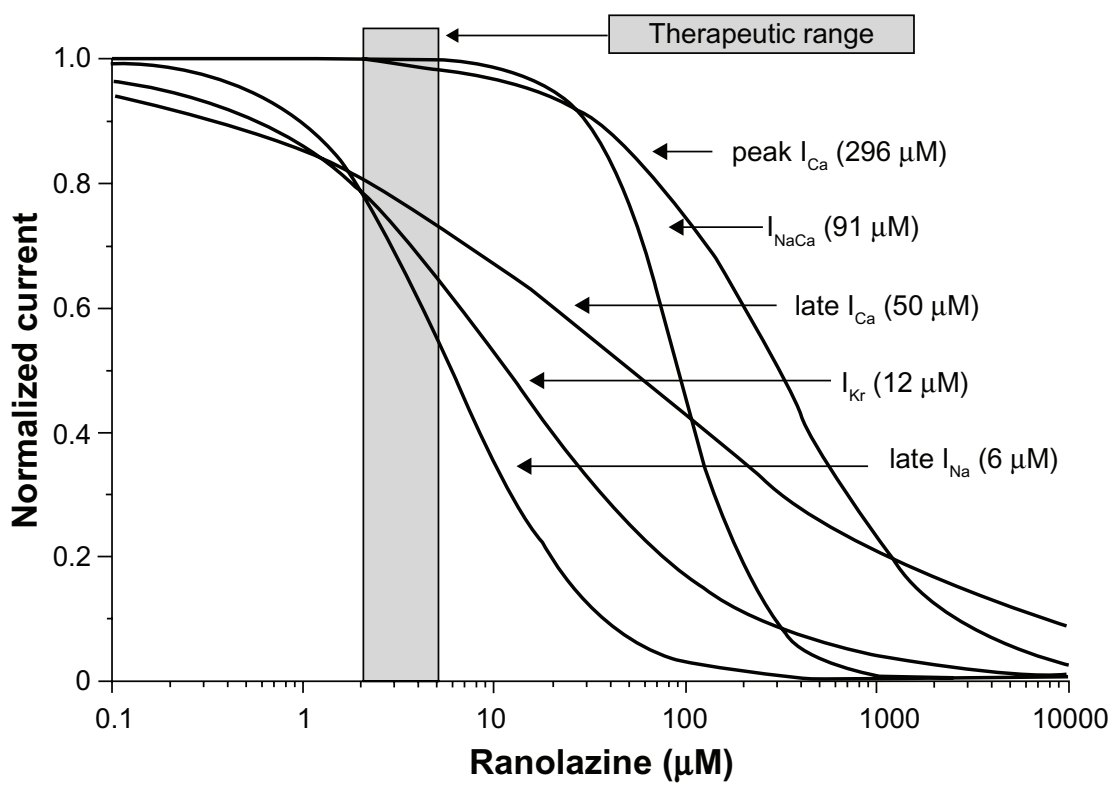

Figure 9 Summary of concentration-response relationships for effect of ranolazine to inhibit inward and outward ion channel currents in canine ventricular myocytes. Numbers inside parentheses are $I_{50}$ values for effect of ranolazine to inhibit rapidly activating delayed rectifier potassium current $\left(I_{K_{\mathrm{r}}}\right)$, late sodium current (late $\left.I_{\mathrm{Na}}\right)$, peak calcium current $\left(I_{C_{a}}\right)$, late $I_{C a}$, and sodium-calcium exchange current $\left(I_{N a}-I_{C_{a}}\right.$. Reprinted with permission from Antzelevitch C, Belardinelli L, Zygmunt AC, et al. Electrophysiological effects of ranolazine, a novel antianginal agent with antiarrhythmic properties. Circulation. 2004; I 10:904-910. ${ }^{21}$ Copyright @ 2004 Wolters Kluwer Health. 
arrhythmias, including ventricular tachycardia, torsades de pointes, and atrial fibrillation. ${ }^{23}$ Multiple experimental animal models involving coronary ischemia and/or exposure to proarrhythmic compounds have demonstrated significant reductions in action potential duration, early afterdepolarizations, delayed afterdepolarizations, transmural dispersion of repolarization, and triggered activity with ranolazine..$^{21-23,25}$

Based on these preclinical findings, several animal and limited human case studies have investigated ranolazine's potential antiarrhythmic role. In a study using isolated canine right atrium, ranolazine equaled amiodarone in preventing acetylcholine-induced atrial fibrillation. ${ }^{42} \mathrm{~A}$ small human case series of seven patients with persistent atrial fibrillation despite ablation and/or conventional antiarrhythmic medications found that four patients remained in sinus rhythm with ranolazine at a mean duration of 27 weeks. ${ }^{43}$ Similarly, in a study of 18 patients with new or paroxysmal atrial fibrillation, ranolazine was administered as a single $2000 \mathrm{mg}$ dose using a "pill in the pocket" strategy. Thirteen of 18 patients converted to sinus rhythm within six hours, suggesting that ranolazine might be useful for acute medical cardioversion of atrial fibrillation. ${ }^{44}$ In a recent published study of isolated right atrial appendages from patients with permanent (or chronic) atrial fibrillation, ranolazine significantly decreased late $\mathrm{I}_{\mathrm{Na}}$, while reversing proarrhythmic activity induced by high $\mathrm{Ca}^{2+}$ or isoprenaline. ${ }^{45}$

Ranolazine has also been applied to various models of ventricular tachycardia and ventricular fibrillation with promising results. In a study of 29 anesthetized pigs, ranolazine administration significantly increased the ventricular fibrillation threshold during invasive electrophysiologic study while having no effect on the defibrillation threshold. ${ }^{46}$ These results

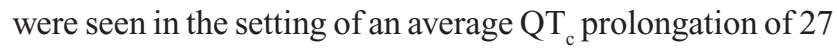
msec. In an animal model of ischemia/reperfusion-induced ventricular arrhythmias, 23 rats underwent transient occlusion of their left coronary arteries with and without ranolazine. While 9/12 (75\%) of placebo-treated rats developed ventricular tachycardia, only $1 / 11$ (9\%) treated with ranolazine developed ventricular tachycardia. ${ }^{47}$ Sixty-seven percent of placebo-treated rats developed ventricular fibrillation compared with $8 \%$ of rats treated with higher doses of ranolazine. In a similar study using a rat model of drug-induced torsades de pointes, ranolazine was shown to prevent the development of torsades de pointes significantly and to terminate torsades de pointes after the first episode. ${ }^{48}$ Human studies with ranolazine and ventricular arrhythmias are limited. In a high-risk group of patients with hereditary long QT syndrome (LQT3- $\triangle \mathrm{KPG}$ ) prone to ventricular arrhythmias and sudden cardiac death, ranolazine shortened the $\mathrm{QT}_{\mathrm{c}}$ by $26 \pm 3 \mathrm{msec}$ $(P<0.0001)$ and improved diastolic relaxation parameters. ${ }^{49}$ Although the preclinical antiarrhythmic data on ranolazine are promising, these studies are limited.

Certainly, the most robust data investigating the potential antiarrhythmic properties of ranolazine came from the MERLIN trial. Of 6560 patients hospitalized with a non-ST elevation acute coronary syndrome enrolled in the trial and randomized to placebo or ranolazine, 6351 (97\%) had continuous Holter monitoring for the first seven days after the index events, and were suitable for evaluation. ${ }^{50}$ Treatment with ranolazine resulted in significantly fewer episodes of ventricular tachycardia lasting $\geq$ eight beats $(P<0.001)$ and supraventricular tachycardia $(P<0.001)$, but had no

Table 3 Rate of tachyarrhythmias detected on CECG monitoring after non-ST-segment elevation MI

\begin{tabular}{|c|c|c|c|c|}
\hline & $\begin{array}{l}\text { Ranolazine, } \\
\text { n (\%) }\end{array}$ & $\begin{array}{l}\text { Placebo, } \\
\text { n (\%) }\end{array}$ & $\begin{array}{l}\mathbf{R R} \\
(95 \% \mathrm{Cl})\end{array}$ & $P$ \\
\hline \multicolumn{5}{|l|}{ Ventricular arrhythmias } \\
\hline $\mathrm{VT} \geq 3$ beats $\geq 100 \mathrm{bpm}$ & $1646(52.1)$ & $1933(60.6)$ & $0.86(0.82,0.90)$ & $<0.001$ \\
\hline $\mathrm{VT} \geq 4$ beats $\geq 100 \mathrm{bpm}$ & $662(20.9)$ & $94 I(29.5)$ & $0.7 I(0.6,0.78)$ & $<0.001$ \\
\hline $\mathrm{VT} \geq 8$ beats (lasting $<30$ s) & $166(5.3)$ & $265(8.3)$ & $0.63(0.52,0.76)$ & $<0.001$ \\
\hline Polymorphic VT $\geq 8$ beats & $38(1.2)$ & $46(1.4)$ & $0.83(0.54,1.28)$ & 0.40 \\
\hline Sustained VT ( $\geq 30 \mathrm{~s})$ & $14(0.44)$ & $14(0.44)$ & $1.01(0.48,2.13)$ & 0.98 \\
\hline Monomorphic & $4(0.13)$ & $7(0.22)$ & $0.59(0.17,2.06)$ & 0.37 \\
\hline Polymorphic & $10(0.32)$ & $7(0.22)$ & I.4I $(0.52,3.78)$ & 0.46 \\
\hline \multicolumn{5}{|l|}{ Supraventricular arrhythmias } \\
\hline New-onset atrial fibrillation & $55(1.7)$ & $75(2.4)$ & $0.74(0.52,1.05)$ & 0.08 \\
\hline $\begin{array}{l}\text { Other SVT } \geq 120 \text { bpm lasting } \\
\text { at least } 4 \text { beats }\end{array}$ & $1413(44.7)$ & $1752(55.0)$ & $0.81(0.77,0.85)$ & $<0.001$ \\
\hline
\end{tabular}

Reproduced with permission from Scirica BM, Morrow DA, Hod H, et al. Effect of ranolazine, an antianginal agent with novel electrophysiological properties, on the incidence of arrhythmias in patients with non-ST-segment elevation acute coronary syndrome: results from the metabolic efficiency with ranolazine for less ischemia in non-ST-elevation acute coronary syndrome-thrombolysis in myocardial infarction 36 (MERLIN-TIMI 36) randomized controlled trial. Circulation. 2007; I 16: 1647-1652.50 Copyright @ 2007 Wolters Kluwer Health. Abbreviations: VT, ventricular tachycardia; SVT, supraventricular tachycardia. 
effect on sustained ventricular tachycardia greater than 30 seconds. It is possible that the absolute number of sustained ventricular tachycardia episodes was too low to reach any significant conclusions (Table 3 ).

There was a trend toward lowering of the occurrence of new-onset atrial fibrillation $(P=0.08)$, while ranolazine significantly reduced the incidence of pauses $\geq$ three seconds compared with placebo $(P=0.01)$. Based on these findings, in conjunction with consistent preclinical data, ranolazine appears to be antiarrhythmic. The $\mathrm{QT}_{\mathrm{c}}$ prolongation seen with ranolazine does not confer an increased arrhythmic risk. Considering that the etiology for many of these arrhythmias is not ischemic in nature, it is plausible that ranolazine's antiarrhythmic properties are related to direct ion channel effects. However, the anti-ischemic effects of ranolazine may contribute benefit for ischemia-related arrhythmias. Subsequent trials are needed to support these findings, including trials investigating the use of ranolazine in patients taking medications known to prolong the $\mathrm{QT}_{\mathrm{c}}$.

\section{Heart failure}

As previously described, ischemia and heart failure lead to abnormally increased late $\mathrm{I}_{\mathrm{Na}}$ current and intracellular calcium overload. ${ }^{9,10}$ Ultimately, excess intracellular calcium leads to dysfunctional myocardial contraction, increased diastolic wall tension, decreased myocardial perfusion, and worsening myocardial function. ${ }^{11}$ By inhibiting the late $\mathrm{I}_{\mathrm{N}_{\mathrm{a}}}$ current, investigations into whether ranolazine can improve both diastolic and systolic cardiac function have been performed.

One of the earliest trials involved 15 patients with previous transmural infarction who underwent invasive hemodynamic and angiographic assessment before and after administration of ranolazine. ${ }^{51}$ In the ischemic but not infarcted segments, ranolazine significantly increased the regional peak filling rate $(P<0.05)$ and regional wall lengthening during the isovolumic relaxation period $(P<0.05)$, which indicates an improvement in regional diastolic function. In a canine model of heart failure induced by sequential intracoronary microembolization, ranolazine reversibly shortened the duration of twitch contractures and completely abolished aftercontractures, effectively reducing diastolic wall "tension". ${ }^{24}$ Further adding to the evidence that ranolazine can improve diastolic function, isolated perfused rat hearts were subjected to transient ischemia followed by reperfusion. Compared with placebo, ranolazine delayed the onset of ischemic contracture, reduced the average left ventricular end diastolic pressure during ischemia and reperfusion, and increased coronary flow at the end of reperfusion. ${ }^{27}$ Several other in vitro studies with ranolazine using isolated rat hearts and isolated myocardium from failing human hearts have shown similarly significant reductions in diastolic wall tension and left ventricular end diastolic pressure, while improving coronary perfusion. ${ }^{45,52-54}$ These studies have inherent limitations, but provide compelling mechanistic and in vitro data to support further investigation and potential use of ranolazine to treat diastolic heart failure.

Beyond diastolic applications, ranolazine has been applied to several systolic heart failure models with intriguing results. Chronic heart failure was induced in 13 dogs using intracoronary microembolization followed by hemodynamic and angiographic analysis before and after ranolazine infusion. ${ }^{14}$ Ranolazine markedly increased the left ventricular ejection fraction $(27 \%$ versus $36 \% ; P=0.0001)$ and stroke volume $(20 \mathrm{~mL}$ versus $26 \mathrm{~mL})$ without altering heart rate or systemic blood pressure.

To investigate ranolazine's effect on left ventricular function and infarct size in the setting of acute ischemia, anesthetized rabbits were pretreated with either ranolazine infusion or vehicle prior to coronary artery occlusion and reperfusion. ${ }^{55}$ Rabbits treated with ranolazine had better global left ventricular ejection fraction $(0.42 \%$ versus $0.33 \% ; P<0.007)$, stroke volume $(1.05 \mathrm{~mL}$ versus $0.78 \mathrm{~mL} ; P<0.01)$ and smaller infarct size $(44 \%$ versus $57 \% ; P<0.04)$. These findings argue that ranolazine may improve left ventricular systolic function and provide myocardial protection during an acute myocardial infarction. Finally, two similar dog models of heart failure induced by intracoronary microembolization found that treatment with ranolazine not only improved left ventricular systolic function while reducing pathologic myocardial remodeling, but these results occurred in the absence of any increase in myocardial oxygen consumption. ${ }^{56,57}$ In summary, by inhibiting the late $\mathrm{I}_{\mathrm{Na}}$ and preventing pathologic intracellular calcium accumulation in heart failure and ischemic conditions, ranolazine may be useful in preventing the abnormal myocardial remodeling that leads to systolic and diastolic heart failure. ${ }^{58}$

\section{Diabetes}

The presence of diabetes in patients with coronary heart disease confers an increased risk of cardiovascular morbidity and mortality. ${ }^{59}$ In the previous clinical trials of ranolazine in patients with stable coronary heart disease, focused analysis of the diabetic population has yielded interesting results. In the CARISA trial, ranolazine produced similar improvements in exercise parameters, nitroglycerin use, 
and anginal frequency in diabetic $(\mathrm{n}=189)$ and nondiabetic $(n=634)$ patients at 12 weeks. Post hoc analysis of the longterm open-label extension period of the CARISA trial found that ranolazine $750 \mathrm{mg}$ and $1000 \mathrm{mg}$ compared with placebo reduced glycosylated hemoglobin $\left(\mathrm{HbA}_{1 \mathrm{c}}\right)$ by $0.48 \pm 0.18 \%$ $(P=0.008)$ and $0.70 \pm 0.18 \%(P=0.0002)$, respectively. ${ }^{37}$ $\mathrm{HbA}_{1 \mathrm{c}}$ was not a preplanned efficacy variable in the CARISA trial, and hypoglycemia therapy was not controlled, but the statistical significance of these findings support an effect of ranolazine.

Subsequently, a prospective evaluation of the effect of ranolazine on hyperglycemia was performed as part of the MERLIN trial. Ranolazine, compared with placebo, significantly reduced $\mathrm{HbA}_{1 \mathrm{c}}$ at four months $(5.9 \%$ versus $6.2 \% ; P<0.001) .{ }^{60} \mathrm{In}$ patients with diabetes treated with ranolazine, $\mathrm{HbA}_{1 \mathrm{c}}$ declined from 7.5 to $6.9(P<0.001)$. Diabetic patients were more likely to achieve $\mathrm{HbA}_{1 \mathrm{c}}<7 \%$ at four months with ranolazine compared with placebo (59\% versus $49 \% ; P<0.001)$ and were less likely to have a $>1 \%$ increase in $\mathrm{HbA}_{1 \mathrm{c}}(14.2 \%$ versus $20.6 \%$ at one year; $P<0.001$ ).

The exact mechanism for the positive glycometabolic effect of ranolazine seen in these trials is unclear. Improved angina control and exercise tolerance with ranolazine can lead to improved cardiovascular health. The amount of exercise needed, however, to reduce the $\mathrm{HbA}_{1 \mathrm{c}}$ to the extent seen in these trials is unlikely to be achieved in this elderly population with angina. ${ }^{37}$ It is also unlikely that ranolazine had any significant effect on erythrocyte lifespan or glucuronidation of hemoglobin that would ultimately affect $\mathrm{HbA}_{1 \mathrm{c}}{ }^{59}{ }^{59}$ Experimental models suggest that ranolazine may increase glucose-stimulated insulin secretion in pancreatic islet cells in response to glucose loading, but this finding has yet to be validated. Ultimately, further studies exploring the mechanism of ranolazine's clinically significant reductions in $\mathrm{HbA}_{1 \mathrm{c}}$ are needed.

\section{Conclusions}

Medical therapy for chronic stable angina underwent little advancement over the past quarter century until ranolazine's approval in 2006. Ranolazine is a late $\mathrm{I}_{\mathrm{Na}}$ inhibitor that prevents pathologic intracellular calcium accumulation in the setting of ischemia and/or heart failure. Multiple clinical trials have demonstrated the clinical utility of ranolazine in controlling angina symptoms and improving exercise tolerance in patients with coronary heart disease. Ranolazine is safe for use in patients with stable coronary heart disease and is without significant hemodynamic effects. Therefore, ranolazine is an ideal antianginal agent, where titration of traditional agents (beta-blockers, calcium channel blockers, or nitrates) is limited by bradycardia, hypotension, or reactive airway disease. Although revised labeling indicates that ranolazine is approved as the initial antianginal agent, the use of betablockers should still be considered as first-line, due to their proven mortality reduction post-myocardial infarction.

The minimal QT $\mathrm{c}_{\mathrm{c}}$ prolongation seen with ranolazine is without apparent clinical sequelae. In fact, investigational applications of ranolazine suggest an antiarrhythmic property. Ranolazine's unique mechanism of action has led to other experiments suggesting that ranolazine may provide beneficial effects on heart failure and diabetes control. Although these latter indications have yet to be validated in large clinical trials, they are promising and warrant further investigation. Ultimately, ranolazine is a safe and effective antianginal agent with a proven safety profile and a novel mechanism of action which may lead to further indications beyond angina control.

\section{Disclosure}

NKW has been a consultant to Gilead Sciences, AstraZeneca, Abbott Women's Advisory Board, Merck, Pfizer, Boston Scientific, Medtronic Women's CV Health Advisory Panel, and Genzyme. She has also received research grants from Pfizer, Merck, NHLBI, Gilead Sciences, Abbott, sanofi-aventis and Eli Lilly.

\section{References}

1. Brunton TL. On the use of nitrite of amyl in angina pectoris. Lancet. 1867;90:97-98.

2. Rosamond W, Flegal K, Furie K, et al. Heart disease and stroke statistics 2008 update: A report from the American Heart Association Statistics Committee and Stroke Statistics Committee. Circulation. 2008;117:e25-e146.

3. Boden WE, O'Rourke RA, Teo KK, et al. Optimal medical therapy with or without PCI for stable coronary disease. $N$ Engl J Med. 2007;356:1503-1516.

4. Frye RL, August P, Brooks MM, et al; BARI 2D Study Group. A randomized trial of therapies for Type 2 diabetes and coronary artery disease. N Engl J Med. 2009;360:2503-2515.

5. Freemantle N, Cleland J, Young P, Mason J, Harrison J. $\beta$ blockade after myocardial infraction: Systematic review and meta regression analysis. Br Med J. 1999;318:1730-1737.

6. Kernis SJ, Harjai KJ, Stone GW, et al. Does beta-blocker therapy improve clinical outcomes of acute myocardial infarction after successful primary angioplasty? J Am Coll Cardiol. 2004;43: 1773-1779.

7. Fraker TD, Fihn SD. 2007 chronic angina focused update of the ACC/ AHA 2002 guidelines for the management of patients with chronic stable angina. J Am Coll Cardiol. 2007;50:2264-2274.

8. Vadnais DS, Wenger NK. Management options in chronic stable angina pectoris: Focus on ranolazine. Clin Med Ther. 2009;1:871-877.

9. Bers DM, Barry WH, Despa S. Intracellular $\mathrm{Na}^{+}$regulation in cardiac myocytes. Cardiovasc Res. 2003;57:897-912.

10. Murphy E, Cross H, Steenbergen C. Sodium regulation during ischemia versus reperfusion and its role in injury. Circ Res. 1999;84: 1469-1470. 
11. Belardinelli L, Antzelevitch C, Fraser H. Inhibition of late (sustained/ persistent) sodium current: A potential drug target to reduce intracellular sodium-dependent calcium overload and its detrimental effects on cardiomyocyte function. Eur Heart J. 2004;6 Suppl I:13-17.

12. Chaitman BR, Skettino SL, Parker JO, et al; MARISA Investigators. Anti-ischemic effects and long-term survival during ranolazine monotherapy in patients with chronic severe angina. J Am Coll Cardiol. 2004;43:1375-1382.

13. MacInnes A, Fairman DA, Binding P, et al. The antianginal agent trimetazidine does not exert its functional benefit via inhibition of mitochondrial long-chain 3-ketoacyl coenzyme A thiolase. Circ Res. 2003;93:e26-e32.

14. Sabbah HN, Chandler MP, Mishima T, et al. Ranolazine, a partial fatty acid oxidation ( $\mathrm{pFOX}$ ) inhibitor, improves left ventricular function in dogs with chronic heart failure. J Card Fail. 2002;8: 416-422.

15. McCormack JG, Barr RL, Wolff AA, Lopaschuk GD. Ranolazine stimulates glucose oxidation in normoxic, ischemic, and reperfused ischemic rat hearts. Circulation. 1996;93:135-142.

16. Létienne R, Vié B, Puech A, Vieu S, Le Grand B, John GW. Evidence that ranolazine behaves as a weak $\beta 1$ - and $\beta 2$-adrenoceptor antagonist in the rat cardiovascular system. Naunyn Schmiedebergs Arch Pharmacol. 2001;363:464-471.

17. Wang P, Fraser H, Lloyd SG, McVeigh JJ, Belardinelli L, Chatham JC. A comparison between ranolazine and CVT-4325, a novel inhibitor of fatty acid oxidation, on cardiac metabolism and left ventricular function in rat isolated perfused heart during ischemia and reperfusion. J Pharmacol Exp Ther. 2007;321:213-220.

18. Hale SL, Shryock JC, Belardinelli L, Sweeney M, Kloner RA. Late sodium current inhibition as a new cardioprotective approach. J Mol Cell Cardiol. 2008;44:954-967.

19. Belardinelli L, Shryock JC, Fraser H. Inhibition of the late sodium current as a potential cardioprotective principle: Effects of the late sodium current inhibitor ranolazine. Heart. 2006;92 Suppl IV:6-14

20. Chaitman BR. Ranolazine for the treatment of chronic angina and potential use in other cardiovascular conditions. Circulation. 2006;113:2462-2472.

21. Antzelevitch C, Belardinelli L, Zygmunt AC, et al. Electrophysiological effects of ranolazine, a novel antianginal agent with antiarrhythmic properties. Circulation. 2004;110:904-910.

22. Sicouri S, Glass A, Belardinelli L, Antzelevitch C. Antiarrhythmic effects of ranolazine in canine pulmonary vein sleeve preparations. Heart Rhythm. 2008;5:1019-1026.

23. Song Y, Shryock JC, Belardinelli L. An increase of late sodium current induces delayed afterdepolarizations and sustained triggered activity in atrial myocytes. Am J Physiol Heart Circ Physiol. 2008; 294:H2031-H209.

24. Undrovinas A, Belardinelli L, Undrovinas NA, Sabbah HN. Ranolazine improves abnormal repolarization and contraction in left ventricular myocytes of dogs with heart failure by inhibiting late sodium current. J Cardiovasc Electrophysiol. 2006;17 Suppl 1:S169-S177.

25. Song Y, Shryock JC, Wu L, Belardinelli L. Antagonism by ranolazine of the pro-arrhythmic effects of increasing late $\mathrm{I}_{\mathrm{Na}}$ in guinea pig ventricular myocytes. J Cardiovasc Pharmacol. 2004;44:192-199.

26. Rousseau MF, Pouleur H, Cocco G, Wolff AA. Comparative efficacy of ranolazine versus atenolol for chronic angina pectoris. Am J Cardiol. 2005;95:311-336.

27. Chaitman BR, Pepine CJ, Parker J, et al. Effects of ranolazine with atenolol, amlodipine, or diltiazem on exercise tolerance and angina frequency in patients with chronic severe angina: A randomized controlled trial. JAMA. 2004;291:309-316.

28. Stone P, Gratsiansky NA, Blokhin A, Huang IZ, Meng L. Antianginal efficacy of ranolazine when added to treatment with amlodipine: The ERICA (Efficacy of Ranolazine in Chronic Angina) trial. J Am Coll Cardiol. 2006;48:566-575.

29. FDA.gov. Ranexa (Ranolazine); updated June 19, 2009. http://www. fda.gov/. Accessed May 21, 2010.
30. Venkataraman R, Belardinelli L, Blackburn B, Heo J, Iskandrian AE. A study of the effects of ranolazine using automated quantitative analysis of serial myocardial perfusion images. JACC Cardiovasc Imaging. 2009;2:1301-1309.

31. Morrow DA, Scirica BM, Karwatowska-Prokopczuk E, et al. Effects of ranolazine on recurrent cardiovascular events in patients with non-ST-elevation acute coronary syndromes. JAMA. 2007;297: 1775-1783.

32. Scirica BM, Morrow DA, Budaj A, et al. Ischemia detected on continuous electrocardiography after acute coronary syndrome: Observations from the MERLIN-TIMI 36 (metabolic efficiency with ranolazine for less ischemia in non-ST-elevation acute coronary syndrome thrombolysis in myocardial infarction 36) trial. J Am Coll Cardiol. 2009;53:1411-1421.

33. Wenger NK, Chaitman B, Vetrovec GW. Gender comparison of efficacy and safety of ranolazine for chronic angina pectoris in four randomized clinical trials. Am J Cardiol. 2007;99:11-18.

34. Wilson SR, Scirica BM, Braunwald E, et al. Efficacy of ranolazine in patients with chronic angina: Observations from the randomized, double-blind, placebo-controlled MERLIN-TIMI (metabolic efficiency with ranolazine for less ischemia in non-ST-segment elevation acute coronary syndromes) 36 trial. J Am Coll Cardiol. 2009;53:1510-1516.

35. Koren MJ, Crager MR, Sweeney M. Long-term safety of a novel antianginal agent in patients with severe chronic stable angina: The ranolazine open label experience (ROLE). J Am Coll Cardiol. 2007;49: 1027-1034.

36. Rich MW, Crager M, McKay CR. Safety and efficacy of extendedrelease ranolazine in patients aged 70 years or older with chronic stable angina pectoris. Am J Geriatr Cardiol. 2007;16:216-221.

37. Timmis AD, Chaitman BR, Crager M. Effects of ranolazine on exercise tolerance and $\mathrm{HbA}_{1 \mathrm{c}}$ in patients with chronic angina and diabetes. Eur Heart J. 2006;27:42-48.

38. Jerling M. Clinical pharmacokinetics of ranolazine. Clin Pharmacokinet. 2006;45:469-491.

39. Jerling M, Abdallah $H$. Effect of renal impairment on multiple-dose pharmacokinetics of extended-release ranolazine. Clin Pharmacol Ther. 2005;78:288-297.

40. Abdallah H, Jerling M. Effect of hepatic impairment on the multipledose pharmacokinetics of ranolazine sustained-release tablets. J Clin Pharmacol. 2005;45:802-809.

41. Jerling M, Huan BL, Leung K, Chu N, Abdallah H, Hussein Z. Studies to investigate the pharmacokinetic interactions between ranolazine and ketoconazole, diltiazem or simvastatin during combined administration in healthy subjects. J Clin Pharmacol. 2005;45:422-433.

42. Burashnikov A, Di Diego JM, Zygmunt AC, Belardinelli L, Antzelevitch C. Atrial-selective sodium channel block as a strategy for suppression of atrial fibrillation. Ann N Y Acad Sci. 2008;1123:105-112.

43. Murdock DK, Overton N, Kersten M, Kaliebe J, Devecchi F. The effect of ranolazine on maintaining sinus rhythm in patients with resistant atrial fibrillation. Indian Pacing Electrophysiol J. 2008;8:175-181.

44. Murkock DK, Kersten M, Kaliebe J, Larrain G. The use of oral ranolazine to convert new or paroxysmal atrial fibrillation: A review of experience with implications for possible "pill in the pocket" approach to atrial fibrillation. Indian Pacing Electrophysiol J. 2009;9: 260-267.

45. Sossalla S, Kallmeyer B, Wagner S, et al. Altered Na+ currents in atrial fibrillation: Effects of ranolazine on arrhythmias and contractility in human atrial myocardium. J Am Coll Cardiol. 2010;55: 2330-2342.

46. Kumar K, Nearing BD, Bartoli CR, Kwaku KF, Belardinelli L, Verrier RL. Effect of ranolazine on ventricular vulnerability and defibrillation threshold in the intact porcine heart. J Cardiovasc Electrophysiol. 2008;19:1073-1079.

47. Dhalla AK, Wang WQ, Dow J, et al. Ranolazine, an antianginal agent, markedly reduces ventricular arrhythmias induced by ischemia and ischemia-reperfusion. Am J Physiol Heart Circ Physiol. 2009;297:H11923-H11929. 
48. Wang WQ, Robertson C, Dhalla AK, Belardinelli L. Antitorsadogenic effects of $( \pm)-N$-(2,6-Dimethyl-phenyl)-(4[2-hydroxy-3-(2-methoxyphenoxy)propyl]-1-piperazine (ranolazine) in anesthetized rabbits. J Pharmacol Exp Ther. 2008;325:875-881.

49. Moss AJ, Zareba W, Schwarz KQ, Rosero S, McNitt S, Robinson JL. Ranolazine shortens repolarization in patients with sustained inward sodium current due to type-3 long QT syndrome. J Cardiovasc Electrophysiol. 2008;19:1289-1293.

50. Scirica BM, Morrow DA, Hod H, et al. Effect of ranolazine, an antianginal agent with novel electrophysiological properties, on the incidence of arrhythmias in patients with non-ST-segment elevation acute coronary syndrome: Results from the metabolic efficiency with ranolazine for less ischemia in non-ST-elevation acute coronary syndrome-thrombolysis in myocardial infarction 36 (MERLIN-TIMI 36) randomized controlled trial. Circulation. 2007;116:1647-1652.

51. Hayashida W, van Eyll C, Rousseau MF, Pouleur H. Effects of ranolazine on left ventricular regional diastolic function in patients with ischemic heart disease. Cardiovasc Drugs Ther. 1994;8:741-747.

52. Hwang H, Arcidi JM Jr, Hale SL, et al. Ranolazine as a cardioplegia additive improves recovery of diastolic function in isolated rate hearts. Circulation. 2009;120 Supp1 1:S16-S21.

53. Wu Y, Song Y, Belardinelli L, Shryock JC. The late $\mathrm{Na}^{+}$current (INa) inhibitor ranolazine attenuates effects of palmitoyl-L-carnitine to increase late INa and cause ventricular diastolic dysfunction. J Pharmacol Exp Ther. 2009;330:550-557.
54. Sossalla S, Wagner S, Rasenack ECL, et al. Ranolazine improves diastolic dysfunction in isolated myocardium from failing human hearts - role of late sodium current and intracellular ion accumulation. J Mol Cell Cardiol. 2008;45:32-43.

55. Hale SL, Leeka JL, Kloner RA. Improved left ventricular function and reduced necrosis after myocardial ischemia/reperfusion in rabbits treated with ranolazine, an inhibitor of the late sodium channel. J Pharmacol Exp Ther. 2006;318:418-423.

56. Rastogi S, Sharov VG, Mishra S, et al. Ranolazine combined with enalapril or metoprolol prevents progressive LV dysfunction and remodeling in dogs with moderate heart failure. Am J Physiol Heart Circ Physiol. 2008;295:H2149-H2155.

57. Chandler MP, Stanley WC, Morita H, et al. Short-term treatment with ranolazine improves mechanical efficiency in dogs with chronic heart failure. Circ Res. 2002;91:278-280.

58. Stone P. Ranolazine: New paradigm for management of myocardial ischemia, myocardial dysfunction, and arrhythmias. Cardiol Clin. 2008;26:603-614.

59. Grundy SM, Benjamin IJ, Burke GL, et al. Diabetes and cardiovascular disease: A statement for healthcare professionals from the American Heart Association. Circulation. 1999;100:1134-1146.

60. Morrow DA, Scirica BM, Chaitman BR, et al. Evaluation of the glycometabolic effects of ranolazine in patients with and without diabetes mellitus in the MERLIN-TIMI 36 randomized controlled trial. Circulation. 2009;119:2032-2039.
Therapeutics and Clinical Risk Management

\section{Publish your work in this journal}

Therapeutics and Clinical Risk Management is an international, peerreviewed journal of clinical therapeutics and risk management, focusing on concise rapid reporting of clinical studies in all therapeutic areas outcomes, safety, and programs for the effective, safe, and sustained use of medicines. This journal is indexed on PubMed Central, CAS,

\section{Dovepress}

EMBase, Scopus and the Elsevier Bibliographic databases. The manuscript management system is completely online and includes a very quick and fair peer-review system, which is all easy to use. Visit http://www.dovepress.com/testimonials.php to read real quotes from published authors. 